\title{
Efficacy of Amino Acids, Vitamins, Minerals, Docosa- hexaenoic Acid, Galactagogue Combination on Lactation: A Postmarketing Surveillance Study
}

\author{
Ami Mehta
}

\begin{abstract}
Aim: To evaluate the efficacy mothers in galactagogue + vitamins + aminoacids in postpartum mothers in terms of quantitative improvement of mothers in milk, patient satisfaction and compliance and overall growth of infant due to addition of nutritive value after 30 days of treatment.
\end{abstract}

Study: A multicentric, noncomparative study was conducted on 1132 patients spread across the country. This study included mothers with inadequate or no breast milk at the time of delivery; and also mothers who had preterm delivery, associated with inadequate milk production. The patients were advised $30 \mathrm{gm}$ of lactancia powder (galactagogue + vitamins + minerals) twice daily along with lukewarm water or milk for at least a month to assess the efficacy and tolerability. The patient's history, mode of delivery and weight of infant were recorded at baseline and the parameters like quantitative improvement in milk, infant growth, patient satisfaction and patient compliance were examined after $3,5,7$ and 30 days of treatment.

Results: Ninety percent patients had a good improvement and $45 \%$ patients with an excellent improvement in lactation after 3 to 5 days of treatment. Among the mothers who had delivered through C-section, it was noted that 223 (46\%) mothers had an excellent improvement in lactation following administration of studied formulation, while 229 (47\%) mothers had a good improvement. In the LBW infants, the mean weight had increased from 2.29 to $3.04 \mathrm{~kg}$, while in the VLBW, the mean weight increased from 1.41 to $2.3 \mathrm{~kg}$.

Conclusion: Due to changing life style and increased prevalence of mothers IMS, or low/inadequate milk secretion, C-section operative cases, preterm delivery cases can be benefited with studied formulation.

Keywords: Galactagogue, Poor lactation, LBW infants, IMS syndrome, Breastfeeding, Vitamins, Minerals, C-section.

How to cite this article: Mehta A. Efficacy of Amino Acids, Vitamins, Minerals, Docosahexaenoic Acid, Galactagogue Combination on Lactation: A Postmarketing Surveillance Study. J South Asian Feder Obst Gynae 2014;6(2):118-122.

\section{Associate Professor}

Department of Obstetrics and Gynecology, Sheth VS General Hospital, Ahmedabad, Gujarat, India

Corresponding Author: Ami Mehta, Associate Professor Department of Obstetrics and Gynecology, Sheth VS General Hospital, Ahmedabad-380006, Gujarat, India, e-mail: amivishal1412@yahoo.co.in
Source of support: This is a multicenter trial conducted in clinics across India, and the data obtained has been analyzed, interpreted and reviewed by Dr Ami Mehta.

Conflict of interest: None declared

\section{INTRODUCTION}

Growth is a substantial part of human life. The infant stage of human life has a pivotal role in the growth and development. It is observed to have maximum growth rate during this phase. Provision of optimal nutrition during this period of life is an essential requirement as it aids in the proper growth and development of the infant.

Breastfeeding plays an important role in providing nutrition to the infants. It has been highly recommended to breastfeed infants in the first 6 months of life. The World Health Organization (WHO), the American Academy of Pediatrics (AAP), the American College of Obstetricians and Gynecologists (ACOG), and the United States Preventive Services Task Force all recommend exclusive breastfeeding for the first 6 months of life. ${ }^{1-4}$ Breastfeeding for all infants is strongly supported by both governmental and medical professional organizations because of its acknowledged benefits with respect to nutrition, gastrointestinal function, host defense and psychological well-being. ${ }^{1,5-8}$

Ironically, in spite of knowing the importance of breastfeeding, and following decades of strategies and tactics in tackling this issue, there is much left to be achieved in reaching the optimum level on a national scale when it comes to breastfeeding. The numbers show that an abysmal 46\% mothers practice exclusive breastfeeding (EBF). ${ }^{9}$ Early breastfeeding initiation was noted only in $40.4 \%{ }^{9} \mathrm{~A}$ major reason for this low numbers has been attributed to a new condition called insufficient milk syndrome (IMS). ${ }^{10}$ Insufficient milk production could be the result of a number of predisposing factors. This usually affects the quality of life of these mothers that can undermine their confidence and elevate anxiety. ${ }^{11}$

Corporate marketing and readily available formula feeds may hamper breastfeeding. The use of formula feeds might be due to many reasons like perceived insufficient milk production, physical barriers, inability to breastfeed at workplace or even as a status symbol owing to the perception 
in developing countries that formula feeds are better than breast milk. ${ }^{12}$

Premature infants have greater nutritional needs to achieve optimal growth in the neonatal period than at any other time of their life. Nutritional support helps to correct growth restriction at birth and to achieve an appropriate rate of weight gain, which is almost twice that of a term infant. ${ }^{13,14}$ However, this is rendered difficult due to many factors. A major impediment to exclusive human milk feeding for premature infants is the difficulty many mothers experience in providing sufficient quantities of milk. The reasons cited for this are emotional stress, difficulty in maintaining supply without a suckling infant, or the biological immaturity of the mammary glands of mothers of premature neonates. Also under nourished mother does not supply sufficient quantities of nutrients, such as protein, calcium, phosphorus, iron and vitamins. ${ }^{15}$

Though nowadays mothers are shifting over to elective cesarean section (C-section) instead of vaginal deliveries, it is not without its own disadvantages. Studies have shown that $\mathrm{C}$-sections can lead to inadequate breastfeeding. Since $\mathrm{C}$-section is associated with infections, atopic disease, obesity, hypertension and diabetes mellitus, it is possible that this may indirectly predispose to conditions, such as reduced breast milk production. ${ }^{16}$

In addition, the national guidelines have also highlighted the importance of anintake of $>550$ calories for the lactating mother apart from the normal intake to sustain the needs of both mother as well as the infant. ${ }^{17}$ In India, owing to the traditional and cultural practices, the nutrition of the lactating mother remains a concern, which in turn affects the quantity and quality of milk to be fed to the infant. Nutritional requirements to support lactation are high and the requirements for many components are greater in lactating women than in those in the nonpregnant state. ${ }^{18}$ Requirements for energy, protein, vitamins $\mathrm{A}, \mathrm{C}, \mathrm{E}, \mathrm{B}_{6}, \mathrm{~B}_{12}$, folate, niacin, riboflavin and thiamine, and the minerals iodine, selenium and zinc are increased in lactating women. The additional protein requirement for the first 6 months of lactation is $25 \mathrm{gm} /$ day. ${ }^{17}$

The current scenario of reduced nutrition in mothers and insufficient breast milk to the infants has led to the formulation of a novel preparation that can aid in meeting this deficiency by nurturing the mother.

Recently, marketed novel preparation that contains the necessary ingredients which nurtures mother as well as increase the milk production along with an increase in the nutritional status of the milk. These ingredients include essential vitamins, minerals, carbohydrates, proteins, fats, sugar, dietary fibers, docosahexaenoic acid (DHA) and galactogogues.
These ingredients have been observed to improve the milk production when used individually as well as in combination. Thus, this combination of all the necessary supplements is beneficial in providing the necessary nutrition to the infant that is deserved without compromising the mother's health.

A post-marketing surveillance (PMS) study was undertaken to evaluate the efficacy of combination of galactagogue, minerals, carbohydrate, protein, dietary fiber, etc. in a large population.

\section{OBJECTIVE}

A large PMS study intended to evaluate the efficacy of galactagougue, vitamins, minerals, dietary fibers, carbohydrate, protein combination in terms of quantitative improvement of mother's milk, patient satisfaction, compliance and growth of the infant due to additional nutrition owing to the intake of the said formulation by the mother was conducted. Parameters like quantitative improvement in milk, infant growth, patient satisfaction and patient compliance were assessed in order to evaluate the efficacy and compliance of galactagogue combination in this population.

\section{MATERIALS AND METHODS}

A multicentric, noncomparative study was conducted in patients spread across the country. This study included mothers with inadequate or no breast milk at the time of delivery, and also mothers who had preterm delivery, associated with inadequate milk production. The patients were advised 30 gm of lactancia powder twice daily along with lukewarm water or milk for at least a month to assess the efficacy.

Group 1 included mothers who had no or inadequate milk production, while group 2 consisted of mothers with suboptimal level milk production or had underweight infants.

The main efficacy outcome assessed in the study included improvement in body weight of the infant observed with the use of galatoctogue and combination (Lactancia from Corona Remedies Pvt. Ltd.) by the mother after 30 days of treatment. Additionally, parameters with regards to lactation were recorded intermittently to assess improvements after 3 , 5 or 7 days respectively. Also, the improvement in lactation after a period of 30 days was assessed.

\section{RESULTS}

A total of 1,132 patients were involved in the study. It was observed that 549 mothers had delivered vaginally and 486 mothers underwent cesarean. The categorization of the patients based on the quantity of the milk production was done as per clinical examination. Thus, $45.4 \%$ mothers who had inadequate lactation were categorized under group 1, 


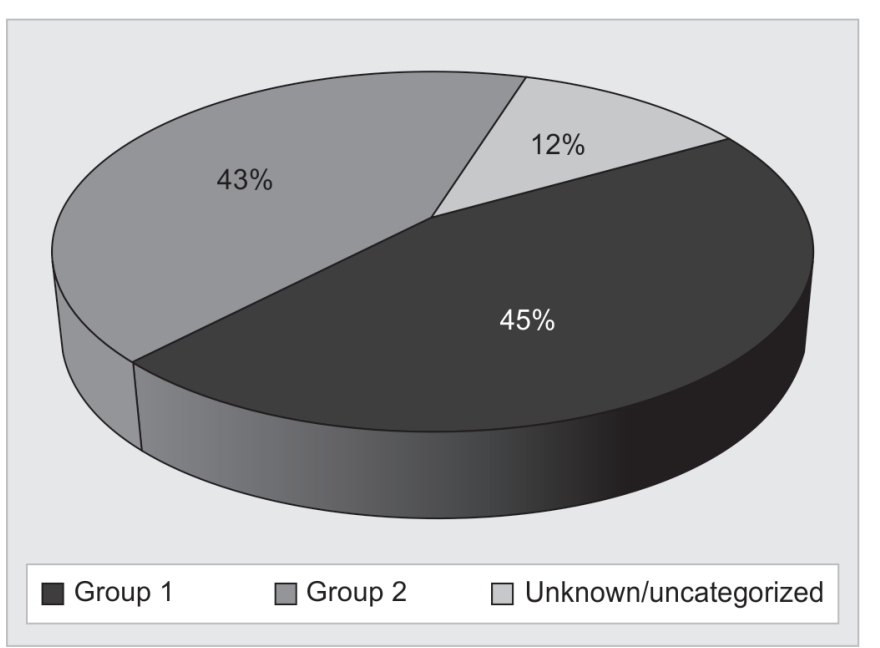

Graph 1: Patient categorization $(p<0.001)$

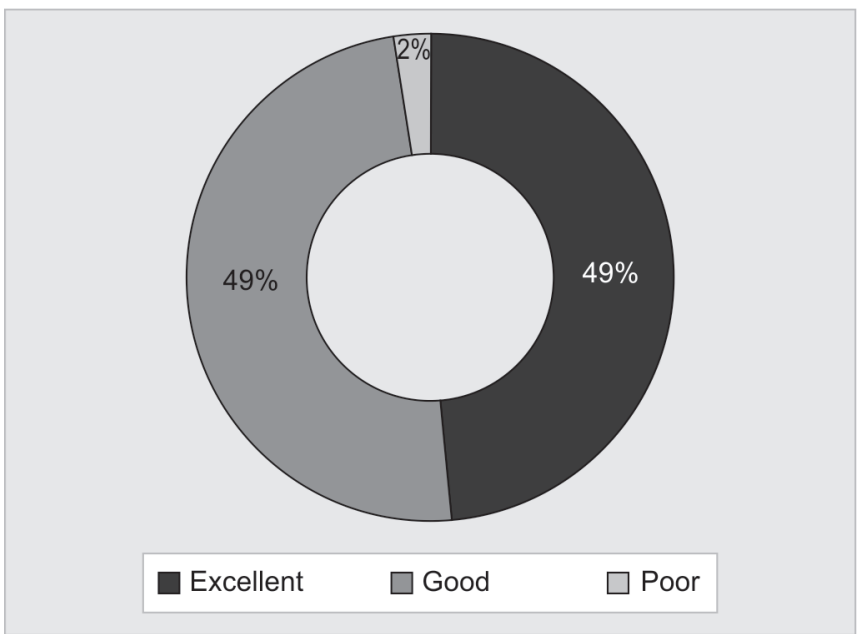

Graph 3: Improvement in lactation with the use of lactancia $(p<0.001)$

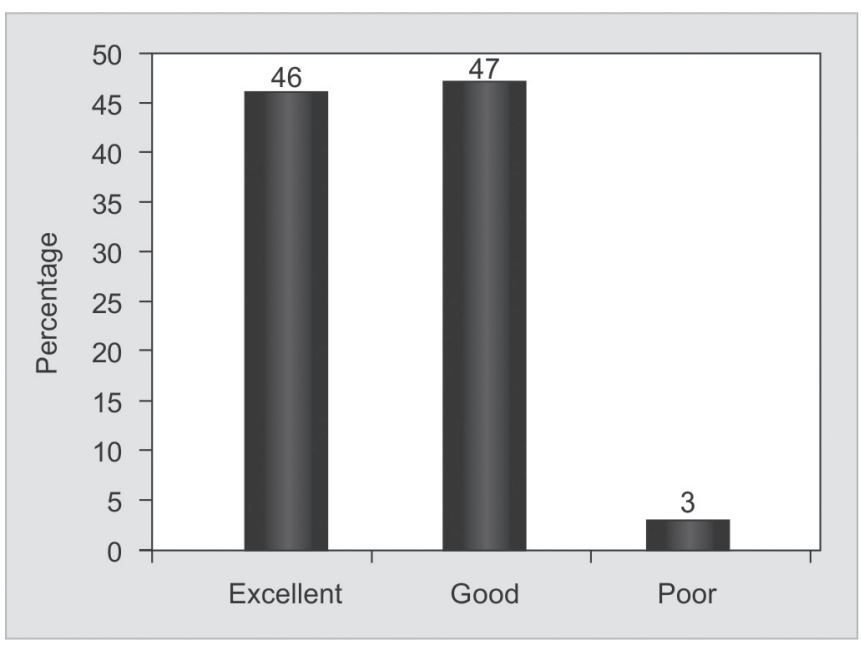

Graph 5: Improvement in lactation with lactancia

and $42.7 \%$ of the mothers who had proper lactation were categorized under group 2 (Graph 1).

It was observed to improve lactation in 1,049 patients within a span of week. Out of that, 492 patients have reported to increased lactation in 3 days of treatment as shown in Graph 2.

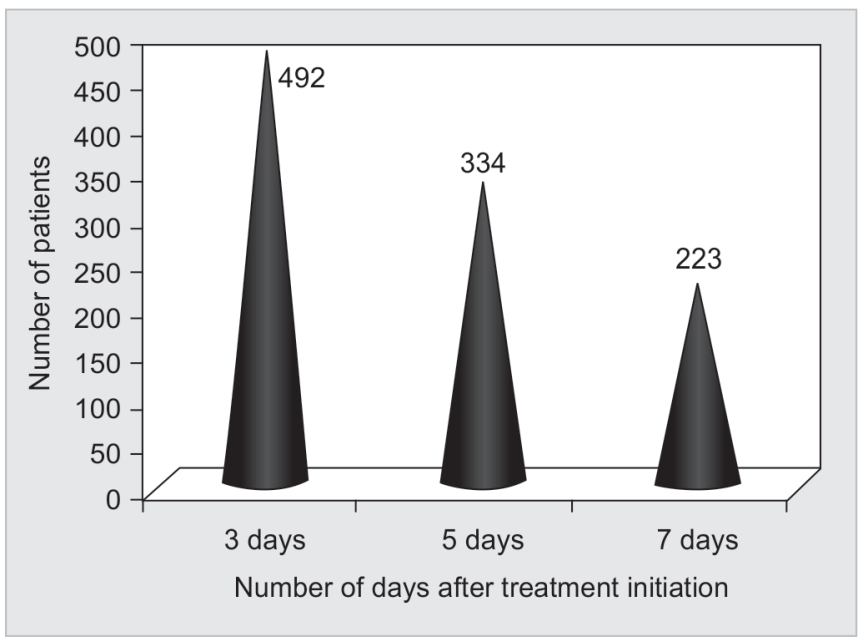

Graph 2: Improvement in lactation $(p<0.001)$

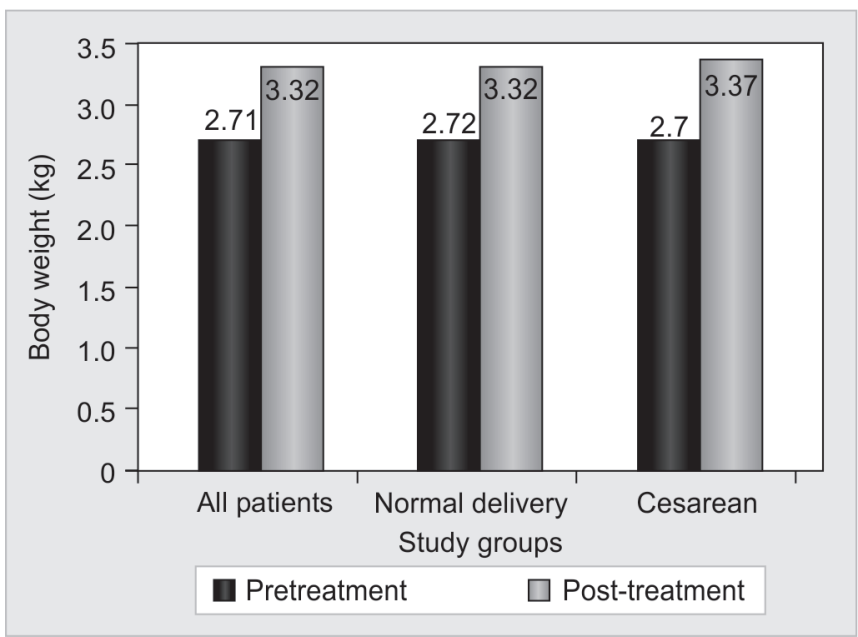

Graph 4: Change in body weight of infants $(p<0.05)$

Ninety percent patients having at least a good improvement and $45 \%$ patients with an excellent improvement as shown in Graph 3. A similar observation was also made with reference to patient compliance, which revealed that $90 \%$ patients had at least a good compliance after supplementation.

The trend in increase in body weight in infants was consistent in comparison to other observations, such as improvement in lactation and patient satisfaction. The bodyweight increased by $600 \mathrm{gm}$ taking into consideration the whole of the study population. Also, a similar trend was observed when subpopulations were taken into consideration as shown in Graph 4.

Among the mothers who had delivered through C-section, it was noted that $223(46 \%)$ mothers had an excellent improvement in lactation following administration of studied formulation, while 229 (47\%) mothers had a good improvement with lactancia. Only $13(3 \%)$ mothers were noted to have poor or no improvement in lactation at the end of 30 days (Graph 5). 


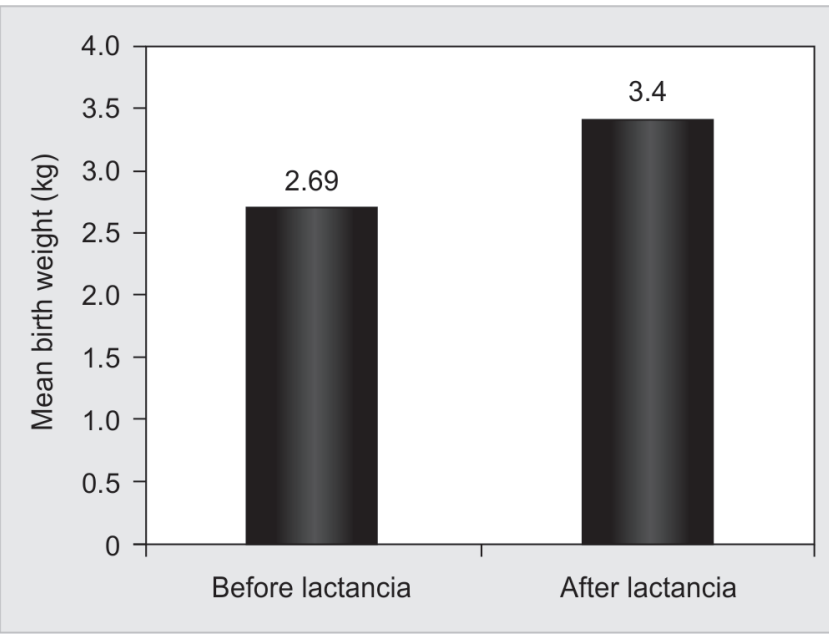

Graph 6: Weight gain in infants following lactancia administration in mothers

The weight gain in infants was analyzed. The mean weight before starting treatment was $2.69 \mathrm{~kg}$, while the mean weight after a month was noted to $3.4 \mathrm{~kg}$ (Graph 6).

Low birth weight (LBW) infants (defined as birth weight of $<2.5 \mathrm{~kg}$ ) and very low birth weight (VLBW) infants (defined as $<1.5 \mathrm{~kg}$ birth weight ${ }^{19}$ were also assessed with regards to weight before initiation of lactancia and after 30 days of treatment. In the LBW infants, the mean weight had increased from 2.29 to $3.04 \mathrm{~kg}$, while in the VLBW, the mean weight increased from 1.41 to $2.3 \mathrm{~kg}$ (Graph 7).

\section{SUMMARY}

These results make it evident that the infants gained weight as required, irrespective of the conditions prevalent in the mother, with the use of lactancia. This was supplemented by the fact that they were very well tolerated, had very minimal safety issues and the compliance was very high.

Lactancia is beneficial in the treatment of IMS and also in other cases where there is insufficient production of milk by the mother. Thus, the requirement for the extra nutrition necessary to breastfeed the infant in the recommended time period of 6 months can be met with the regular usage of lactancia.

\section{CONCLUSION}

Lantancia can be good alternative supplementation to mother's of low birth babies which help infant to grow rapidly. Based on the study, lactancia is effective supplementation for the lactating mothers.

\section{ACKNOWLEDGMENT}

We highly appreciate and thank the doctors who spared their valuable time to conduct this study.

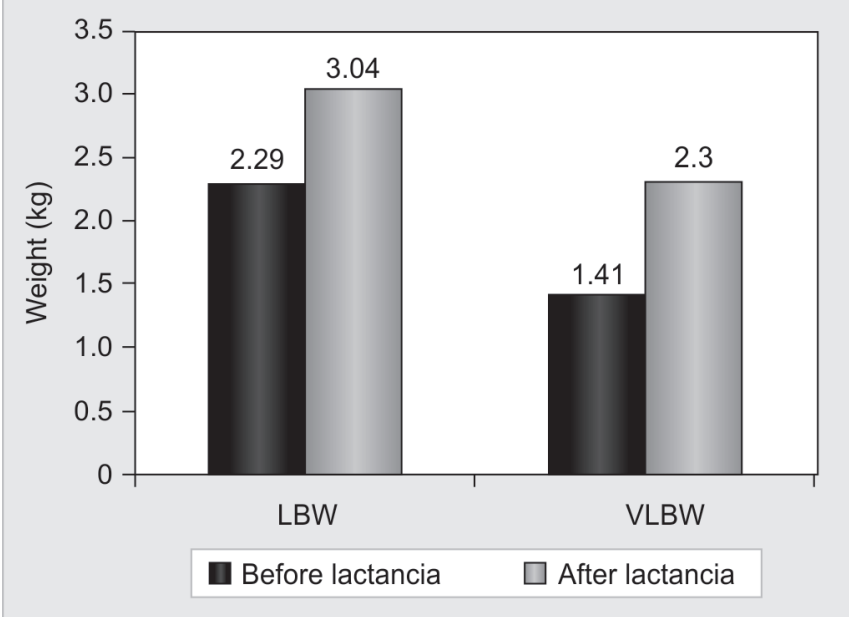

Graph 7: Effect of lactancia on weight of LBW and VLBW infants

\section{REFERENCES}

1. Breastfeeding and the use of human milk. Pediatrics 2012 March 1;129(3):e827-e841.

2. World Health Organization. Global Strategy for Infant and Young Child Feeding (2003). Available at: http://www.who.int/ nutrition/publications/infantfeeding/en/index.html.

3. US. Preventive Services Task Force. Primary care interventions to promote breastfeeding: US. Preventive Services Task Force recommendation statement. Ann Intern Med 2008;149(8):560-564.

4. Breastfeeding: maternal and infant aspects ACOG Committee Opinion No. 361. College of Obstetricians and Gynecologists. Obstet Gynecol 2007;109:479-480.

5. Department of Health and Human Services, Office on Women's Health. Breastfeeding: HHS Blueprint for Action on Breastfeeding. US Department of Health and Human Services, Washington, DC 2000.

6. American College of Obstetricians and Gynecologists. Breastfeeding: maternal and infant aspects. ACOG Educational Bulletin 258, American College of Obstetricians and Gynecologists, Washington, DC; 2000.

7. Chung M, Raman G, Trikalinos $\mathrm{T}$, et al. Interventions in primary care to promote breastfeeding: an evidence review for the US Preventive Services Task Force. Ann Intern Med 2008; 149(8):565-582.

8. Kramer MS, Kakuma R. Optimal duration of exclusive breastfeeding. Cochrane Database Syst Rev 2012;8:CD003517.

9. UNICEF India. Statistics. Available at: http://www.unicef.org/ infobycountry/india_statistics.html. Accessed on: 4th April 2014.

10. Hill PD. Insufficient milk supply syndrome. NAACOGS Clin Issu Perinat Womens Health Nurs 1992;3(4):605-612.

11. Gussler JD, Briesemeister LH. The insufficient milk syndrome: a biocultural explanation. Med Anthropol 1980;4:145-174.

12. Zeitlyn S, Rowshan R. Privileged knowledge and mothers 'perceptions': the case of breast-feeding and insufficient milk in Bangladesh. Med Anthropol 1997;11(1):56-68.

13. Schanler RJ, Garza C, Nichols BL. Fortified mothers' milk for very low birth weight infants: results of growth and nutrient balance studies. J Pediatr 1985;107:437.

14. Butte NF, Garza C, Smith EO, et al. Human milk intake and growth in exclusively breast-fed infants. J Pediatr 1984;104(2): 187-195. 
15. Schanler RJ. Human milk feeding and fortification of human milk for premature infants. Available at: http://210.212.194.104:2069/ contents/human-milk-feeding-and-fortification-of-human-milkfor-premature-infants? source $=$ search_result\&search=breast + feeding\&selectedTitle $=49 \sim 150$. Accessed on: 4th April 2014.

16. Clement S. Psychological aspects of caesarean section. Best Pract Res Clin Obstet Gynaecol 2001;15(1):109-126.

17. DRI, Dietary Reference Intakes: For Energy, Carbohydrate, Fiber, Fat, Fatty Acids, Cholesterol, Protein, and Amino
Acids (Macronutrients). Standing Committee on the Scientific Evaluation of Dietary Reference Intakes, Food, and Nutrition Board, Institute of Medicine. National Academy Press, Washington, DC; 2005.

18. Picciano MF. Nutrient composition of human milk. Pediatr Clin North Am 2001;48(1):53-57.

19. Guidelines on optimal feeding of low birth weight infants in low and middle-income countries. Available at: http://www.who.int/ maternal_child_adolescent/documents/9789241548366.pdf. Accessed on: 6th April 2014. 